Supporting Information for

\title{
Active-targeting NIR-II Phototheranostics in Multiple tumor models using Platelet- camouflaged Nanoprobes
}

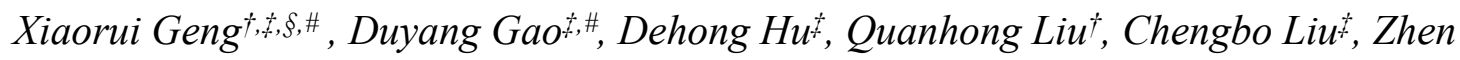

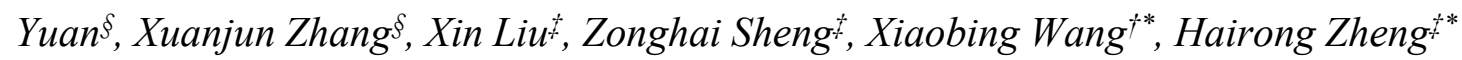

$\dagger$ Key Laboratory of Medicinal Resources and Natural Pharmaceutical Chemistry, Ministry of Education, College of Life Sciences, Shaanxi Normal University, Xi'an 710119, P. R. China.

$\$$ Paul C. Lauterbur Research Center for Biomedical Imaging, Key Laboratory for Magnetic Resonance and Multimodality Imaging of Guangdong Province, Shenzhen Key Laboratory of Ultrasound Imaging and Therapy, CAS key laboratory of health informatics, Institute of Biomedical and Health Engineering, Shenzhen Institute of Advanced Technology, Chinese Academy of Sciences, Shenzhen, 518055, P. R. China.

$\S$ Faculty of Health Sciences, University of Macau, Taipa, Macau SAR, P. R. China.

*Corresponding authors. E-mail: wangxiaobing@snnu.edu.cn. (Xiaobing Wang); hr.zheng@siat.ac.cn (Hairong Zheng) 


\section{Supplementary Table and Figures}

Table S1 Summary of probes for photoacoustic imaging combined with photothermal therapy under $1064 \mathrm{~nm}$ laser irradiation.

\begin{tabular}{|c|c|c|c|c|}
\hline Number & Nanoparticles & Tumor models & Active-targeting & Ref \\
\hline 1 & POM & $\begin{array}{l}\text { Subcutaneous } 4 \mathrm{~T} 1 \\
\text { tumor model }\end{array}$ & No & 1 \\
\hline 2 & SC@G & $\begin{array}{l}\text { Subcutaneous } 4 \mathrm{~T} 1 \\
\text { tumor model }\end{array}$ & No & 2 \\
\hline 3 & $\mathrm{Nd}^{\mathrm{III}}-\mathrm{IP}$ & $\begin{array}{c}\text { Subcutaneous Hela } \\
\text { tumor model }\end{array}$ & No & 3 \\
\hline 4 & $\mathrm{Cu}_{2-\mathrm{x}} \mathrm{S}-\mathrm{PEG}$ & $\begin{array}{c}\text { Subcutaneous } 4 \mathrm{~T} 1 \\
\text { tumor model }\end{array}$ & No & 4 \\
\hline 5 & WTO & $\begin{array}{c}\text { Subcutaneous 4T1 } \\
\text { tumor model }\end{array}$ & No & 5 \\
\hline 6 & Polipo-IR & $\begin{array}{c}\text { Subcutaneous HepG2 } \\
\text { tumor model }\end{array}$ & No & 6 \\
\hline 7 & $\begin{array}{l}\text { NiP-PHNPs- } \\
\text { DOX }\end{array}$ & $\begin{array}{c}\text { Subcutaneous U14 } \\
\text { tumor model }\end{array}$ & No & 7 \\
\hline 8 & $\mathrm{Au} / \mathrm{Ag} \mathrm{NRs}$ & MRSA & No & 8 \\
\hline 9 & TiN-PVP & $\begin{array}{l}\text { Subcutaneous 4T1 } \\
\text { tumor model }\end{array}$ & No & 9 \\
\hline 10 & SPNs3 & $\begin{array}{l}\text { Subcutaneous } 4 \mathrm{~T} 1 \\
\text { tumor model }\end{array}$ & No & 10 \\
\hline 11 & OSPA & $\begin{array}{c}\text { Subcutaneous 4T1 } \\
\text { tumor model }\end{array}$ & No & 11 \\
\hline 12 & AINPs & $\begin{array}{c}\text { Subcutaneous HepG2 } \\
\text { tumor model }\end{array}$ & No & 12 \\
\hline 13 & Au nanocoral-3c & $\begin{array}{c}\text { Subcutaneous Hela } \\
\text { tumor model }\end{array}$ & No & 13 \\
\hline 14 & SPNs & $\begin{array}{c}\text { Subcutaneous U87 } \\
\text { tumor model }\end{array}$ & No & 14 \\
\hline 15 & FePd-Cys & $\begin{array}{l}\text { Subcutaneous 4T1 } \\
\text { tumor model }\end{array}$ & No & 15 \\
\hline 16 & AuPB & $\begin{array}{l}\text { Subcutaneous } 4 \mathrm{~T} 1 \\
\text { tumor model }\end{array}$ & No & 16 \\
\hline 17 & $\begin{array}{l}\mathrm{HBP} / \mathrm{PTX} \\
\text { micelles }\end{array}$ & $\begin{array}{l}\text { Subcutaneous 4T1 } \\
\text { tumor model }\end{array}$ & No & 17 \\
\hline 18 & IR-SS & $\begin{array}{c}\text { Subcutaneous } 4 \mathrm{~T} 1 \\
\text { tumor model }\end{array}$ & No & 18 \\
\hline 19 & $\mathrm{CS}-\mathrm{RuO}_{2} \mathrm{NPs}$ & $\begin{array}{c}\text { Subcutaneous MCF-7 } \\
\text { tumor model }\end{array}$ & Yes & 19 \\
\hline 20 & TSIO & $\begin{array}{c}\text { Subcutaneous 4T1 } \\
\text { tumor model }\end{array}$ & Yes & 20 \\
\hline
\end{tabular}




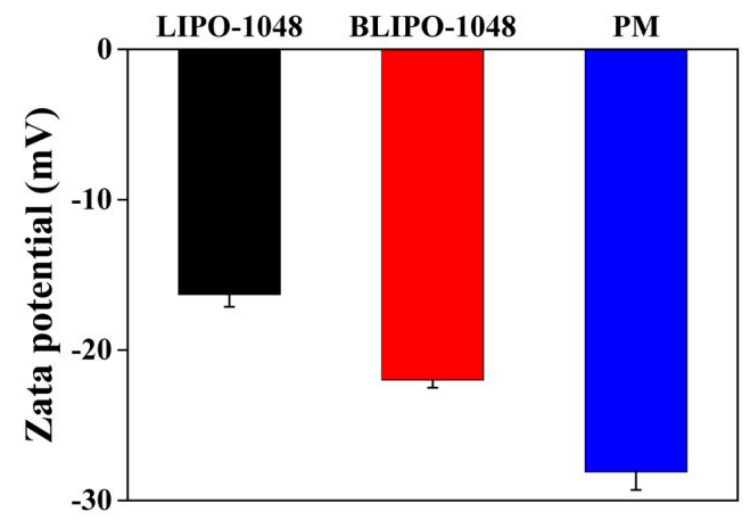

Figure. S1 Zeta potential of LIPO-1048, BLIPO-1048 and PM. Bars represent the mean \pm s.d. $(\mathrm{n}=3)$. 


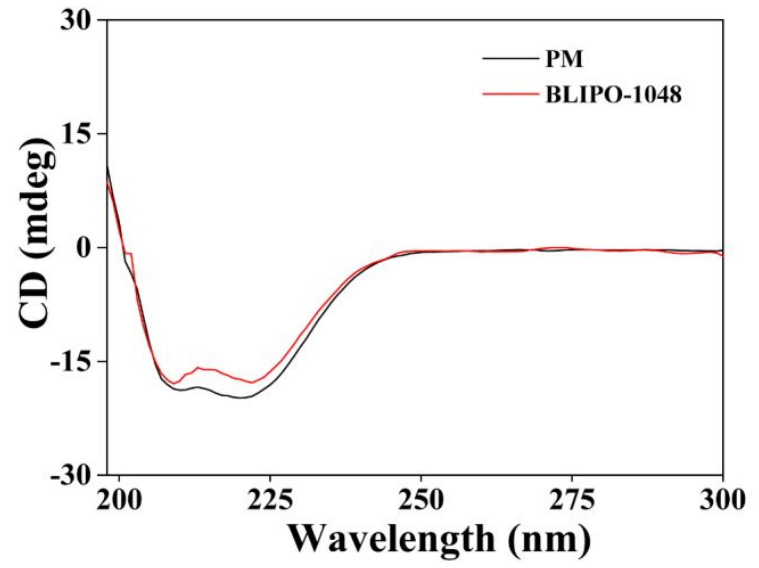

Figure. S2 CD spectra of BLIPO-1048 and PM. 


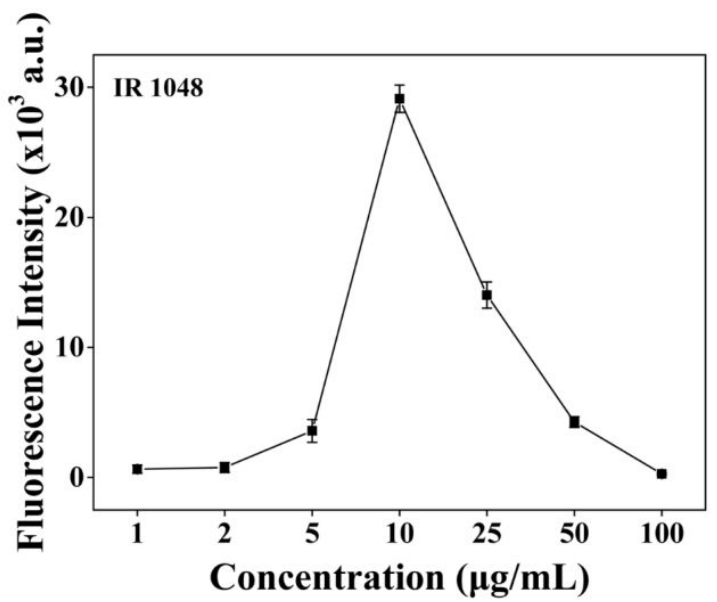

Figure. S3 Relationship between the concentration of IR1048 and the fluorescence intensity. Bars represent the mean \pm s.d. $(\mathrm{n}=3)$. 


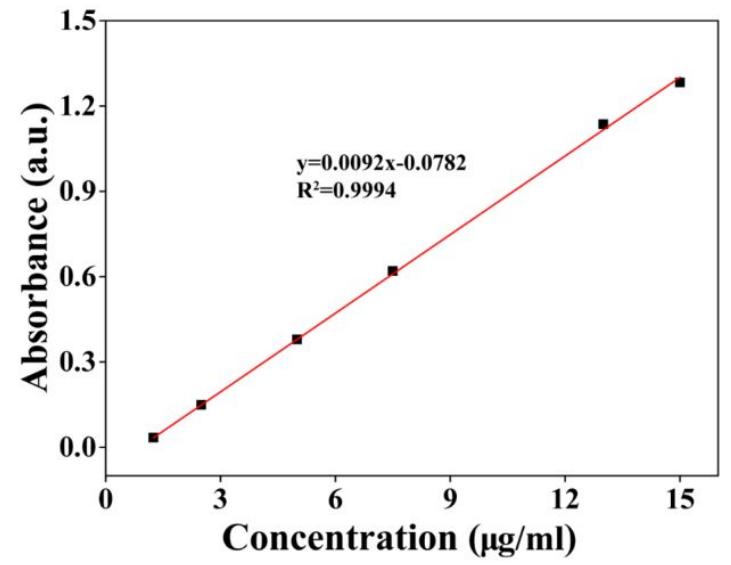

Figure. S4 Standard curve of IR 1048 in 90\% dimethyl sulfoxide solution. 
(a)

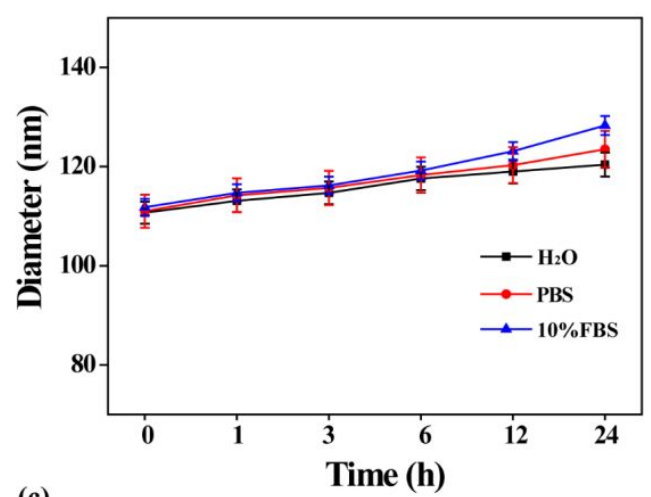

(c)

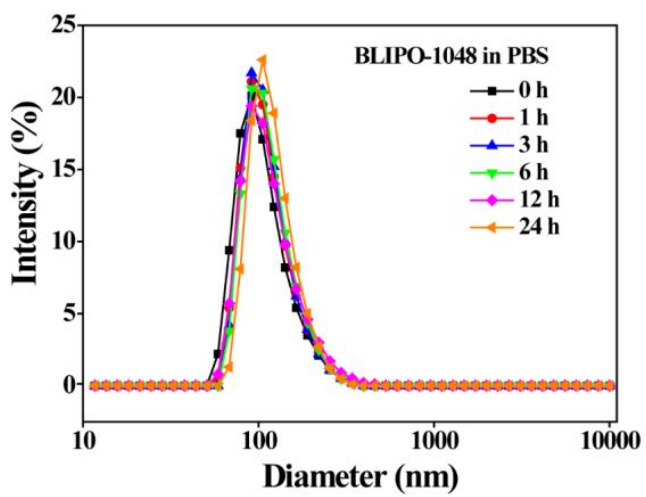

(b)

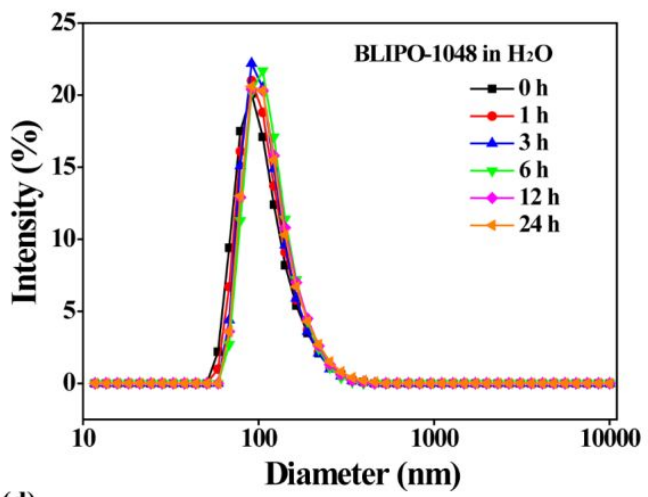

(d)

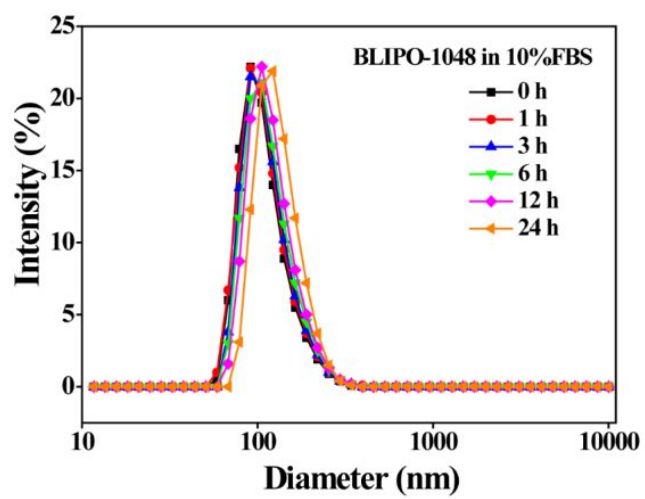

Figure. S5 (a-d) Hydrodynamic diameters of BLIPO-1048 in $\mathrm{H}_{2} \mathrm{O}$, PBS and 10\% FBS after $24 \mathrm{~h}$ of incubation. All bars represent the mean \pm s.d. $(n=3)$. 


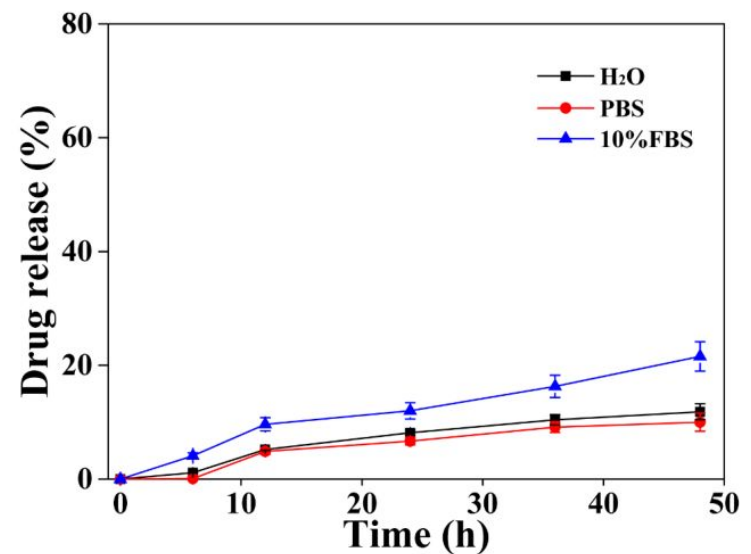

Figure. S6 Drug release profiles of BLIPO-1048 in $\mathrm{H}_{2} \mathrm{O}$, PBS and 10\% FBS after $48 \mathrm{~h}$ of incubation. Bars represent the mean \pm s.d. $(n=3)$. 
(a)

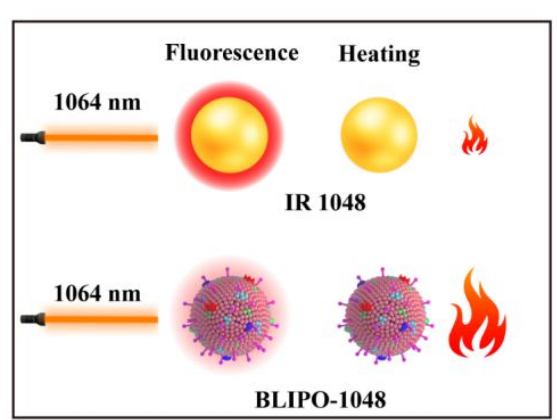

(c)

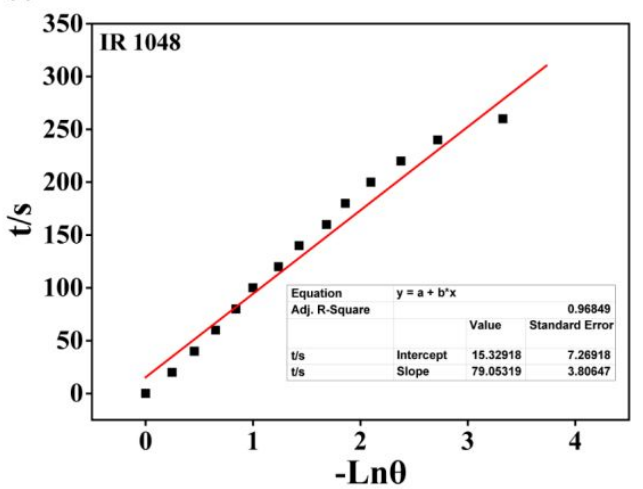

(e)

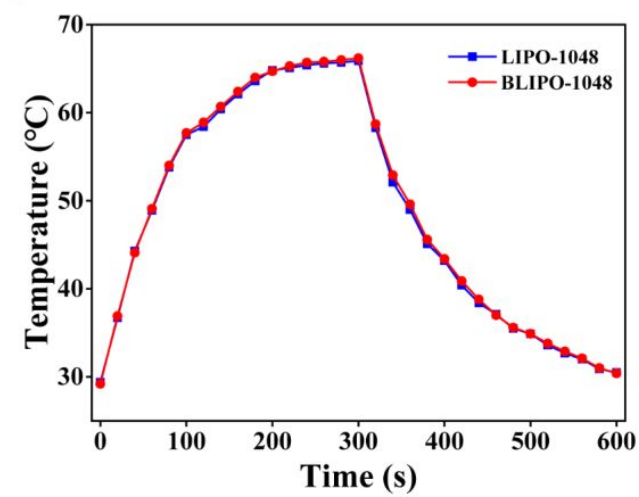

(b)

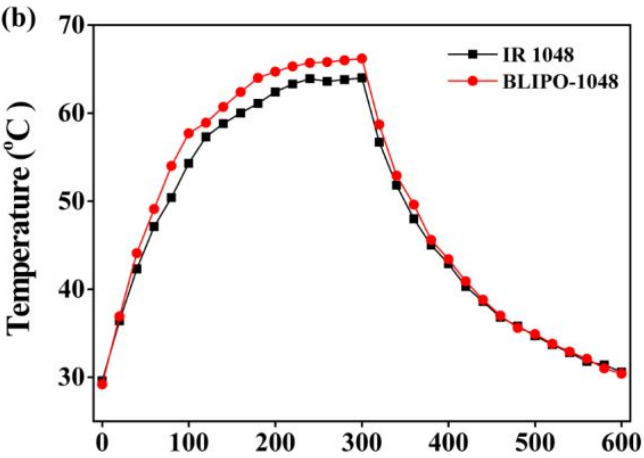

(d)

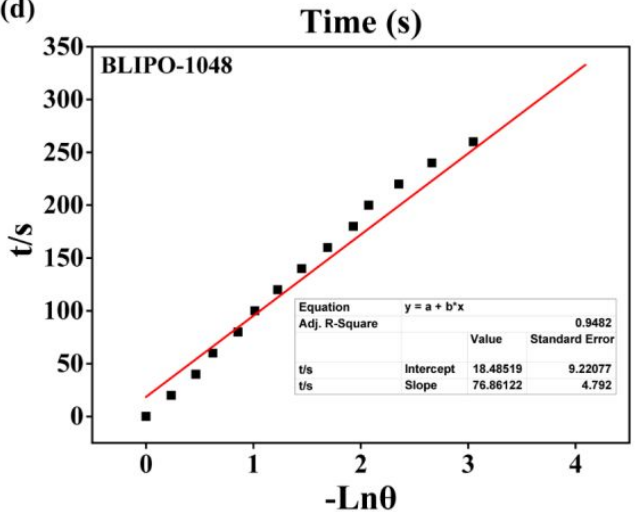

(f)

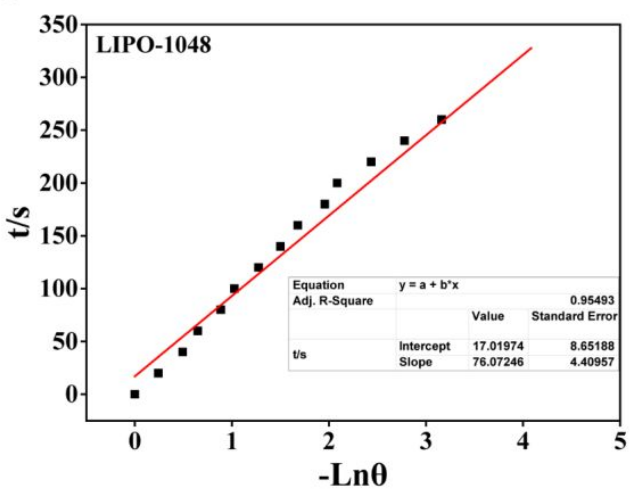

Figure. S7 (a) Schematic diagram of BLIPO-1048's photothermal conversion efficiency superior to IR 1048. (b) Temperature change of BLIPO-1048 and IR 1048 within 600s exposure. (c-d) Photothermal conversion efficiencies of IR1048 and BLIPO-1048. (e) Temperature change of BLIPO-1048 and LIPO-1048 in 600s. (f) Photothermal conversion efficiency of LIPO-1048. 


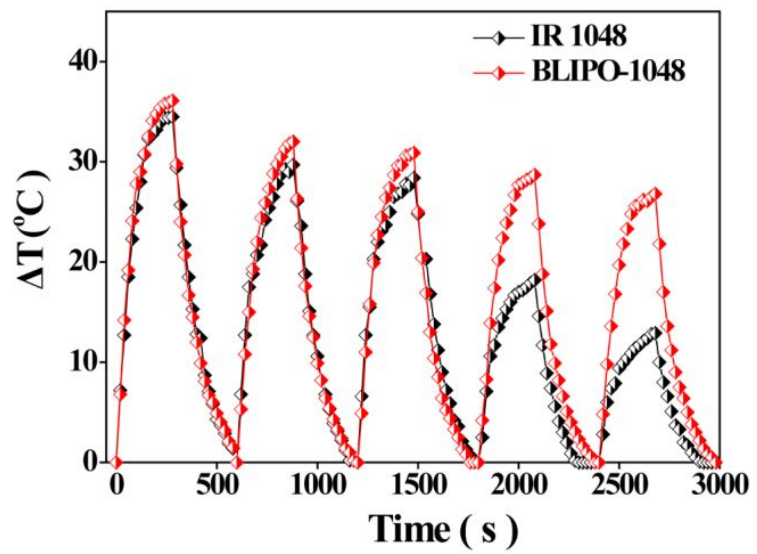

Figure. S8 Photothermal conversion stability of BLIPO-1048 and IR 1048. 


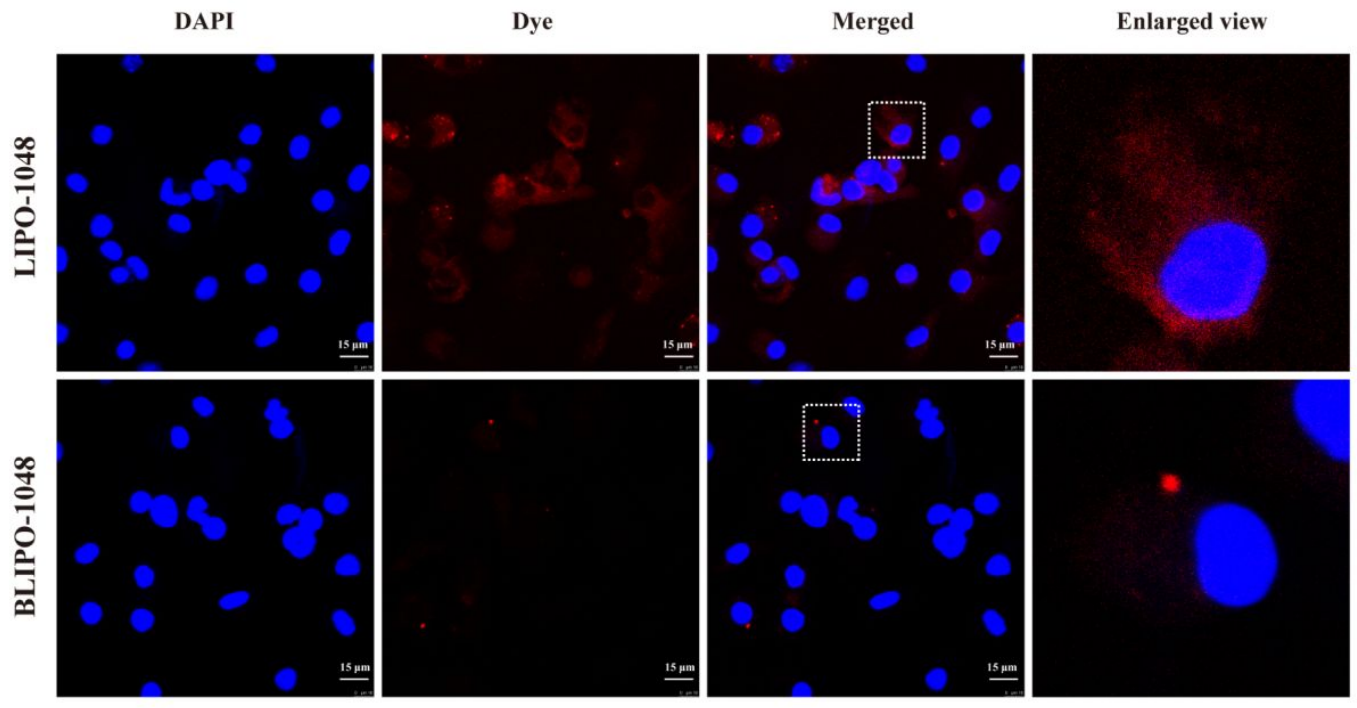

Figure. S9 CLSM images of primary macrophages treated with LIPO-1048 and BLIPO-1048 for $4 \mathrm{~h}$ (scale bar $=15$ $\mu \mathrm{m}, \mathrm{C}_{\text {Dye (ICG) }}=5 \mu \mathrm{g} / \mathrm{mL}$ ). 


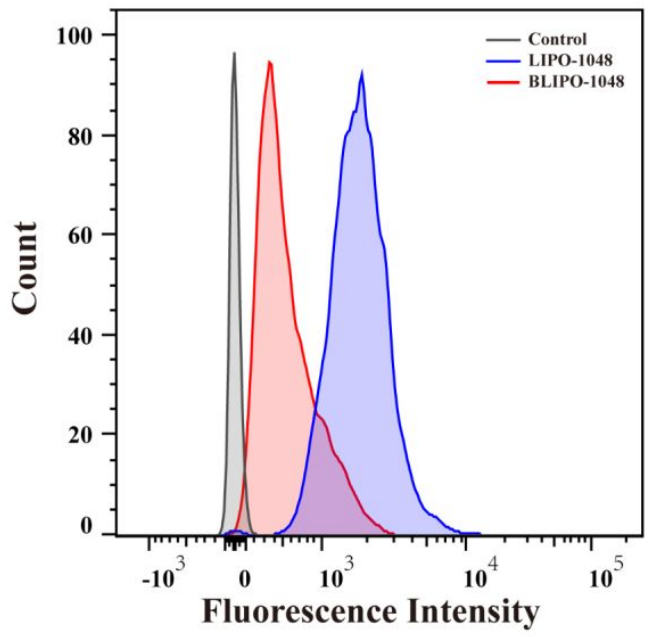

Figure. S10 Flow cytometry analysis of RAW264.7 cells treated with LIPO-1048 and BLIPO-1048 for 4 h. $\mathrm{C}_{\text {Dye }}$ (ICG) $=5 \mu \mathrm{g} / \mathrm{mL}$. 
(a)

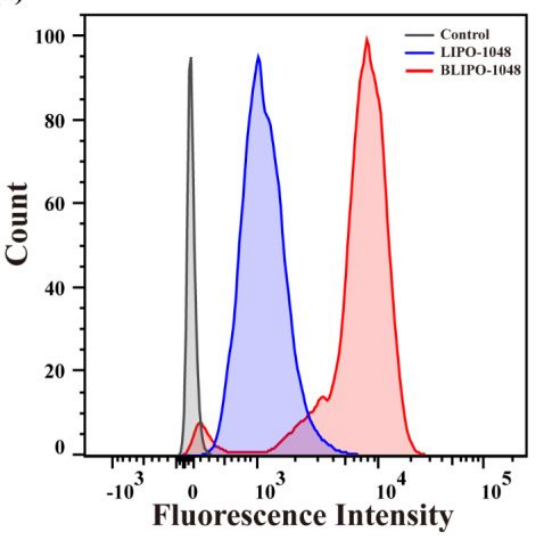

(b)

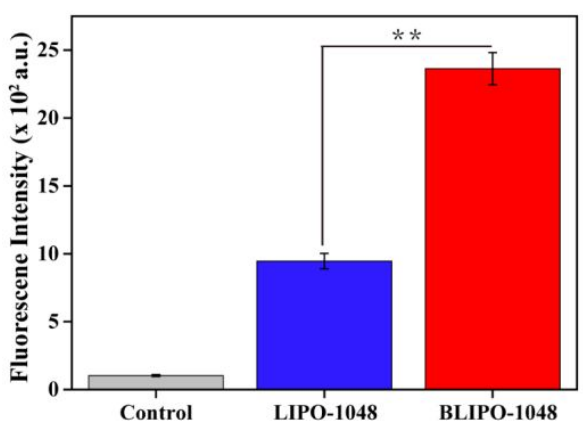

Figure. S11 Flow cytometry analysis (a) and fluorescence intensity (b) of C6 cells treated with LIPO-1048 and BLIPO-1048 for $4 \mathrm{~h}$. $\mathrm{C}_{\text {Dye }(\mathrm{ICG})}=5 \mu \mathrm{g} / \mathrm{mL}$. Bars represent the mean \pm s.d. $(\mathrm{n}=3)$. 


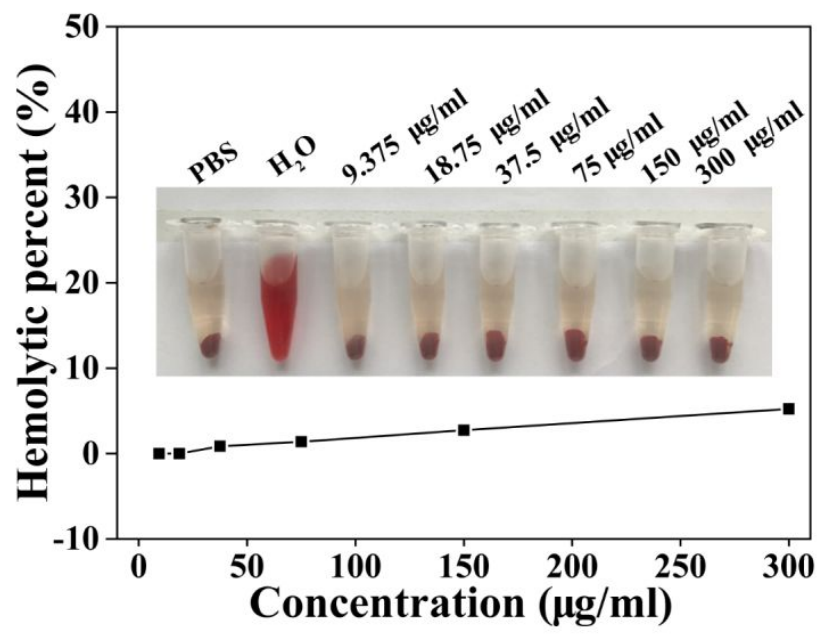

Figure. S12 Hemolysis rate of BLIPO-1048. Bars represent the mean \pm s.d. $(n=3)$. 


\section{References}

(1) Han, Y.; Qu, B.; Li, J.; Zhang, X.; Peng, X.; Li, W.; Zhang, R., A Simple POM Clusters for in vivo NIR-II Photoacoustic Imaging-Guided NIR-II Photothermal Therapy. J. Inorg. Biochem. 2020, 209, 111121, DOI:10.1016/j.jinorgbio.2020.111121.

(2) Yang, C.; Younis, M. R.; Zhang, J.; Qu, J.; Lin, J.; Huang, P., Programmable NIR-II Photothermal-Enhanced Starvation-Primed Chemodynamic Therapy using Glucose OxidaseFunctionalized Ancient Pigment Nanosheets. Small. 2020, 16 (25), e2001518, DOI:10.1002/smll.202001518.

(3) Li, Y.; Lin, J.; $\quad$ Wang, P.; Luo, Q.; Lin, H.; Zhang, Y.; Hou, Z.; Liu, J.; Liu, X., Tumor Microenvironment Responsive Shape Reversal Self-Targeting Virus-Inspired Nanodrug for ImagingGuided Near-Infrared-II Photothermal Chemotherapy. ACS Nano. 2019, 13 (11), 12912-12928, DOI:10.1021/acsnano.9b05425.

(4) Hu, R.; Fang, Y.; Huo, M.; Yao, H.; Wang, C.; Chen, Y.; Wu, R., Ultrasmall Cu2-XS Nanodots as Photothermal-Enhanced Fenton Nanocatalysts for Synergistic Tumor Therapy at NIR-II Biowindow. Biomaterials. 2019, 206, 101-114, DOI:10.1016/j.biomaterials.2019.03.014.

(5) Gao, K.; Tu, W.; Yu, X.; Ahmad, F.; Zhang, X.; Wu, W.; An, X.; Chen, X.; Li, W., Wdoped TiO2 Nanoparticles with Strong Qbsorption in the NIR-II Window for Photoacoustic/CT DualModal Imaging and Synergistic Thermoradiotherapy of Tumors. Theranostics. 2019, 9 (18), 5214-5226, DOI:10.7150/thno.33574.

(6) Chen, Q.; Chen, J.; He, M.; Bai, Y.; Yan, H.; Zeng, N.; Liu, F.; Wen, S.; Song, L.; Sheng, Z.; Liu, C.; Fang, C., Novel Small Molecular Dye-Loaded Lipid Nanoparticles with Efficient Near-Infrared-II Absorption for Photoacoustic Imaging and Photothermal Therapy of Hepatocellular Carcinoma. Biomater Sci. 2019, 7 (8), 3165-3177, DOI:10.1039/c9bm00528e.

(7) Liu, Y.; Zhen, W.; Wang, Y.; Liu, J.; Jin, L.; Zhang, T.; Zhang, S.; Zhao, Y.; Yin, N.; Niu, R.; Song, S.; Zhang, L.; Zhang, H., Double Switch Biodegradable Porous Hollow Trinickel Monophosphide Nanospheres for Multimodal Imaging Guided Photothermal Therapy. Nano Lett. 2019, 19 (8), 5093-5101, DOI:10.1021/acs.nanolett.9b01370.

(8) Mei, Z.; Gao, D.; Hu, D.; Zhou, H.; Ma, T.; Huang, L.; Liu, X.; Zheng, R.; Zheng, H.; Zhao, P.; Zhou, J.; Sheng, Z., Activatable NIR-II Photoacoustic Imaging and Photochemical Synergistic Therapy of MRSA Infections using Miniature Au/Ag Nanorods. Biomaterials. 2020, 251,

120092 , DOI:10.1016/j.biomaterials.2020.120092.

(9) Wang, C.; Dai, C.; Hu, Z.; Li, H.; Yu, L.; Lin, H.; Bai, J.; Chen, Y., Photonic Cancer Nanomedicine Using the Near Infrared-II Biowindow Enabled by Biocompatible Titanium Nitride nanoplatforms. Nanoscale Horiz. 2019, 4 (2), 415-425, DOI:10.1039/c8nh00299a.

(10) Zhang, W.; Sun, X.; Huang, T.; Pan, X.; Sun, P.; Li, J.; Zhang, H.; Lu, X.; Fan, Q.; Huang, W., $1300 \mathrm{~nm}$ Absorption Two-Acceptor Semiconducting Polymer Nanoparticles for NIR-II Photoacoustic Imaging System Guided NIR-II Photothermal Therapy. Chem. Commun. 2019, 55 (64), 9487-9490, DOI:10.1039/c9cc04196f.

(11) Yin, C.; Li, X.; Wen, G.; Yang, B.; Zhang, Y.; Chen, X.; Zhao, P.; Li, S.; Li, R.; Wang, L.; Lee, C.-S.; Bian, L., Organic Semiconducting Polymer Amphiphile for Near-Infrared-II Light-Triggered Phototheranostics. Biomaterials. 2020, 232, 119684 , DOI:10.1016/j.biomaterials.2019.119684.

(12) Cao, Y.; Song, W.; Jiang, Q.; Xu, Y.; Cai, S.; Wang, S.; Yang, W., Nanoparticles from 
Ancient Ink Endowing a Green and Effective Strategy for Cancer Photothermal Therapy in the Second Near-Infrared Window. ACS Omega. 2020, 5 (11), 6177-6186, DOI:10.1021/acsomega.0c00252.

(13) Jia, J.; Liu, G.; Xu, W.; Tian, X.; Li, S.; Han, F.; Feng, Y.; $\quad$ Dong, X.; Chen, H., FineTuning the Homometallic Interface of Au-on-Au Nanorods and Their Photothermal Therapy in the NIRII Window. Angew Chem Int Ed Engl. 2020, 59(34), 14443-14448, DOI:10.1002/anie.202000474.

(14) Wen, G.; Li, X.; Zhang, Y.; Han, X.; Xu, X.; Liu, C.; Chan, K. W. Y.; Lee, C.-S.; Yin, C.; Bian, L.; Wang, L., Effective Phototheranostics of Brain Tumor Assisted by Near-Infrared-II Light-Responsive Semiconducting Polymer Nanoparticles. ACS Appl Mater Interfaces. 2020, 12 (30), 33492-33499, DOI:10.1021/acsami.0c08562.

(15) Lyu, M.; Zhu, D.; Duo, Y.; Li, Y.; Quan, H., Bimetallic Nanodots for Tri-Modal CT/MRI/PA Imaging and Hypoxia-Resistant Thermoradiotherapy in the NIR-II Biological Windows. Biomaterials. 2020, 233, 119656, DOI:10.1016/j.biomaterials.2019.119656.

(16) Zhou, J.; Jiang, Y.; Hou, S.; Upputuri, P. K.; Wu, D.; Li, J.; Wang, P.; Zhen, X.; Pramanik, M.; Pu, K.; Duan, H., Compact Plasmonic Blackbody for Cancer Theranosis in the NearInfrared II Window. ACS Nano. 2018, 12 (3), 2643-2651, DOI:10.1021/acsnano.7b08725.

(17) Zhang, Y.; Tao, H.; Li, Q.; Sheng, W.; Xu, Y.; Hao, E.; Chen, M.; Liu, Z.; Feng, L., Surfactant-Stripped J-Aggregates of azaBODIPY Derivatives: All-In-One Phototheranostics in the Second Near Infrared Window. $J$ Control Release. 2020, 326, 256-264, DOI:10.1016/j.jconrel.2020.07.017.

(18) Li, S.; Deng, Q.; Zhang, Y.; Li, X.; Wen, G.; Cui, X.; Wan, Y.; Huang, Y.; Chen, J.; Liu, Z.; Wang, L.; Lee, C.-S., Rational Design of Conjugated Small Molecules for Superior Photothermal Theranostics in the NIR-II Biowindow. Adv. Mater. 2020, 32(33), e2001146, DOI:10.1002/adma.202001146.

(19) Liu, Z.; Qiu, K.; Liao, X.; Rees, T. W.; Chen, Y.; Zhao, Z.; Ji, L.; Chao, H., NucleusTargeting Ultrasmall Ruthenium(iv) Oxide Nanoparticles for Photoacoustic Imaging and LowTemperature Photothermal Therapy in the NIR-II Window. Chem. Commun. 2020, 56 (20), 3019-3022, DOI:10.1039/c9cc09728g.

(20) Fu, Q.; Li, Z.; Ye, J.; Li, Z.; Fu, F.; Lin, S.-L.; Chang, C. A.; Yang, H.; Song, J., Magnetic Targeted Near-Ifrared II PA/MR Imaging Guided Photothermal Therapy to Trigger Cancer Immunotherapy. Theranostics. 2020, 10 (11), 4997-5010, DOI:10.7150/thno.43604.

(21) Guo, B.; Sheng, Z.; Hu, D.; Liu, C.; Zheng, H.; Liu, B., Through Scalp and Skull NIR-II Photothermal Therapy of Deep Orthotopic Brain Tumors with Precise Photoacoustic Imaging Guidance. Adv. Mater. 2018, 30 (35), e1802591, DOI:10.1002/adma.201802591. 